\title{
Early Clinical Exposure in Physiology
}

\author{
Gopal Krushna Pal', Nivedita Nanda
}

\section{Gopal Krushna Pal*, Nivedita Nanda}

\section{Jawaharlal Institute of Postgradate Medical Education and Research, (JIPMER), Puducherry, INDIA.}

\section{Correspondence}

Prof. Gopal Krushna Pa Senior Professor, Physiology, Jawaharlal Institute of Postgraduate Medical Education and Research, (JIPMER), Puducherry-605001, INDIA.

Phone: +91-9344291160

Email: drgkpal@gmail.com

\section{History}

- Submission Date: 20-12-2018

- Review completed: 13-01-2019;

- Accepted Date: 24-01-2019.

\section{DOI : 10.5530/ijcep.2019.6.1.1}

\section{Copyright}

(C) 2019 Phcog.Net. This is an openaccess article distributed under the terms of the Creative Commons Attribution 4.0 International license.

\section{INTRODUCTION}

In India, the Medical Council of India (MCI) has taken steps to implement competency-based undergraduate curriculum from 2019 throughout the country. In this new curriculum, MCI has recommended for introduction of Early Clinical Exposure (ECE) as part of training of $1^{\text {st }}$ MBBS students. ${ }^{[1]}$ ECE is a method adopted by medical educationists to foster exposure of medical students early in their first year in medical college to patients through genuine human contact, not through simulations. It is the new paradigm of medical education and training. Its sounds easier to integrate basic science subjects for clinical years student as they can easily revert back to basic science subjects and further improve their competency levels. However, it is more challenging to introduce clinical years subjects into preclinical years which is the formative years for an undergraduate student to learn the basics and therefore overburdening with clinical disciplines has to be carefully avoided. ECE is an appropriate solution for this challenge. Life of a medical student in the very first year is both challenging and yet interesting. There is a demand of a comprehensive and integrated approach for solving the issues pertaining to practical skill-based knowledge in medicine. Therefore, the sooner the students are exposed to the reality of their profession, the better they will appreciate the role of first MBBS topics as the building blocks in their MBBS career.

The main objective of this method is to provide a context for basic science learning with socio-clinical relevance. ECE can be done with the objective of how to approach a patient and how to observe the important features of a disease that helps to learn the physiological basis of medicine.

\section{POSSIBLE METHODS}

ECE can be implemented by:

1. Out-Patient Department (OPD) Visit: Students can be taken to OPD to see how doctors deal with the patients on daily basis.

2. Indoor Visit: Students can be taken to hospital wards to see how sisters, paramedical staff and doctors deal with the indoor patients and take care of them.

3. Case Presentation: According to the systembased modules taught to them, few important cases may be presented to them related to that system.

4. Case Discussion: Presentation and discussion of important cases may be done in batches by bringing patients to physiology department or taking students to hospital wards.

5. Problem-based Learning (PBL): $\mathrm{PBL}$ is one of the good methods of ECE. Class on a topic can be started with problem (case scenario) of that topic. For example, for heart functions related to myocardial contractility and heart failure, a case scenario of heart failure may be presented to the students and discussion may be initiated. Even, a case (patient) of heart failure may be presented to student and discussion may be started on various aspects of myocardial functions.

6. OSPE and OSCE: Objective Structured Practical Examination (OSPE) and Objective Structured Clinical Examination (OSCE) are better methods of ECE. OSPE for the first time was introduced in a textbook in Physiology by GK Pal in his Practical Physiology book in 1999 and since then it has become a standard method of imparting skill, assessing skill and imbibing practical/ clinical techniques in clinical physiology.

7. Demonstrating Clinical-based Investigation: Students should be given demonstration of clinical investigations such as tilt-table, autonomic function tests, HRV analysis, BPV analysis, EEG and ECG recording on actual hospital patients.

8. Simulations: Demonstration through simulations (virtual patients) should be avoided and if not, should be very minimal in ECE.

To start with the ambulatory and volunteering patients with no severe complications may be brought to a classroom setting and the basic science teacher can discuss the case in front of the students in classroom. Even the concerned clinician treating / attending the patient can be involved in this discussion. A proper history taking session and minimum possible clinical examination such as heart rate, BP recording or spirometry etc can also be done. The patient can be escorted back to clinic/ward by other faculties while the teacher can continue with other relevant lab investigations and probable management of the case.

However, not all cases can be brought and demonstrated in a classroom setting and hence visits to $\mathrm{OPD} /$ wards of the hospital attached to the medical college can be arranged in small batches. This provides better opportunity of seeing more no of cases and have more real-life interaction with the patients by the learners. For example, 
for the Hematology Module in Physiology, students can visit OPD under departments of Gynecology/Medicine and observe signs of anemia, petechiae, interact with patients with bleeding disorders for eliciting case history and analyze their case records for lab investigations and treatment under supervision of a Gynecology/Medicine professor. The visit has to be prearranged in small batches by coordination between the Department of Physiology and Gynecology/Medicine etc.

For respiratory module, the visit can be arranged with either Medicine or Pulmonary medicine and students can observe patients with asthma, watch PFT being done on patients, can analyze ABG reports etc. For renal module students may visit the Medicine or Nephrology clinic and observe cases with edema, renal failure, dialysis etc.

For gastrointestinal module they can visit Department of Medicine and interact with patients having jaundice. ${ }^{[2]}$

Physiology faculty should be the key person in implementing ECE in Physiology

ECE should primarily be imparted by faculty of Physiology, not by faculty of clinical departments. This will give the real inputs to students to think the relevance of physiology and physiologists in clinical medicine. If ECE classes are taken by clinicians, students will start realizing that physiolo- gists are less relevant in clinical medicine. Moreover, opportunity should not be given to clinicians to say that they can teach physiology and physiologists have no role in clinical medicine. ECE is an opportunity for physiologists to be integrated with clinical medicine and students to realize the role of physiology in shaping up them as physicians.

\section{CONCLUSION}

ECE makes the learners aware of the real disease burden in the society and their future roles and responsibilities as a physician. It creates more interest as a future doctor and motivates the learners to think beyond the physiology class rooms, reading the disease process. It helps remembering features of the disease, the drug names and their mechanisms to pass the examinations and help them start thinking in terms of finding new clinical research in medicine.

\section{REFERENCES}

1. Competency based undergraduate curriculum for the Indian medical graduate2018. A Publication of MCl, New Delhi, India. 2018;(1).

2. Pal GK, Nivedita N, Pal P. Competency-based Integrated Curriculum and Early Clinical Exposure in Physiology. In: Comprehensive Textbook of Medical Physiology, Second Edn., Jaypee Publications, New Delhi. 2019;1377-9.

Cite this article: Pal GK, Nivedita Nanda. Early Clinical Exposure in Physiology. Int J Clin Exp Physiol. 2019; 6(1):1-2. 